\title{
Ethics and Economics of Tobacco Farming: A Case Study of Rural Bangladesh
}

\author{
Habibur Rahman ${ }^{1}$, Jani Parvin ${ }^{2}$ \\ ${ }^{1}$ (Lecturer,Department of Economics, Begum Rokeya University, Rangpur 5400, Bangladesh) \\ ${ }^{2}$ (Assistant Professor, Department of Economics, Begum Rokeya University, Rangpur-5400,Bangladesh)
}

\begin{abstract}
Tobacco is being dealt as one of the major cash crops which are largely grown in Kushtia, Chittagong Hill, and northern regions of Bangladesh. Actually it is a non-food plant used as a basic raw material for products that is proved to be harmful for health, environment and society. Tobacco is both dangerous and addictive. Its production thus raises ethical questions. The study is aimed to estimate the factors affecting tobacco yield and investigate whether any ethical issues influence the production behavior of tobacco farmer in Lalmonirhat district. Both primary and secondary data are used in this paper. Primary data is collected from 100 farmers using simple random sampling method from Aditmari upazila of Lalmonirhat district. are used .To estimate the influencing factors including ethics on the tobacco yield, both multiple linear and double log regression model are used. Tabular method is followed to describe the socio-economic profile and explore ethical consideration of tobacco farmers regarding its cultivation. The result shows that actually major farmers have no ethical concerns about tobacco farming. It also reveals that the majorities of tobacco farmers are reluctant to leave its production though they claim that tobacco production is unethical. The linear regression result of tobacco yield shows that the variables fertilizer, pesticides, seed, labors, support from the company, and land quality are positively significant to affect the tobacco yield. From the normative point of view, ethical concern of the farmers would be negatively related with their tobacco yield. But the paper finds an insignificant relation between ethics and tobacco yield.
\end{abstract}

Key words: Ethics, farmers, rural, tobacco farming, and tobacco yield.

\section{INTRODUCTION}

Bangladesh is predominantly an agricultural country with over $45 \%$ of its total labor force is employed in agriculture and about 17\% of the national GDP is derived from this sector (BBS, 2016). Employment in tobacco farming is responsible for less than $0.5 \%$ of agricultural employment in Bangladesh.Tobacco is being dealt as one of the major cash crops which are grown throughout the country, with the largest tobacco growing areas including Rangpur, Lalmonirhat, Kushtia, and Chittagong Hill (Barkat et al., 2012). Tobacco farming has been introduced since mid-sixties of the last century in this country into the fields where food crops were grown. Its production expanded widely after liberation of 1971 at Teesta silt in Rangpur area. Tobacco is grown in agricultural land, but actually it is not an agricultural crop. In the context of Bangladesh, agriculture means where farmers are involved in the decision for choosing the crops and its consumption and marketing. Where tobacco is a non-food plant and basic raw material for products such as cigarette, bidi and other smokeless tobacco that is proved to be harmful for health, environment and society(Akhter,2011).There are also many hazards of tobacco farming in terms of health, environment, and society. Health threats include the large amount of pesticides used on the crop, as well as illnesses relating to the handling of raw tobacco leaves. Continuous exposure to the smell of nicotine emanating from the fields leads to dizziness, nausea and vomiting. Dermal absorption of nicotine while harvesting the wet green leaves leads to an illness called "green tobacco sickness" or GTS (Nahar and Debra,2007).Tobacco is the second major cause of death globally causing 5.4 million premature deaths each year out of which 1.2 million deaths occur in the South-East Asia region. It is predicted that within 21st century one billion people will die from tobacco use (WHO Report, 2008). Bangladesh has a double burden of tobacco production and consumption. Smoking causes about $25 \%$ of all deaths in Bangladeshi men aged 25 to 69 years and an average loss of seven years of life per smoker (Alam et al., 2012).A huge quantity of fuel wood is needed for curing of tobacco leaves, which releases poisonous smoke in the environment. Consequently trees are logged indiscriminately and the environment is polluted by the poisonous smoke (Geist,1999). In Bangladesh, huge areas of forests in the Chittagong Hill Tract region have disappeared over the past few years, and a substantial portion has been tobacco-related deforestation (Nahar and Debra,2007). Environmental degradation is also caused by the tobacco plant which leaches nutrients from the soil, as well as pollution from pesticides and fertilizers applied to tobacco fields (Geist, 1999). Tobacco farming 
is harmful for livestock, poultry, biodiversity also.It is also harmful for social environment. Due to its easy accessibility and social acceptability, there are now more young women and teenagers having access to cigarettes and hence getting addicted. Children get much information from early ages and being addicted with tobacco in various forms. Child labor often occurs in tobacco-growing areas. By taking children out of school to work in the fields, parents are reducing their children's future opportunities for a better life (Geneva: ECLT report, 2011). In addition, tobacco competes for land suitable for food production. It is clear that tobacco is both dangerous and addictive. Its production and use thus might raise ethical questions from normative point of view.Tobacco production has been expanded significantly in the country. According to BBS statistics, tobacco farming areas and its production has risen by $76 \%$ and $134 \%$ respectively during the period from $2007-08$ to 2014-15 (BBS,2012 \&'16). Lalmonirhat is a district of northern region of Bangladesh, is one of the hotspots where tobacco farming is popular. In recent years, a significant amount of cultivable land are been used for tobacco farming in this district. In this situation farming of non-food crops like tobacco by replacing food-crop land is a threat on our food security (The Daily Star). According to the Lalmonirhat Agriculture Extension Department (AED), Farmers' tobacco cultivation in Lalmonirhat has been increased from 4 thousand hectares to 25 thousand hectares during 2002- 2013. In this area, tobacco farming is also causing threat on health, environment and society. But they are producing tobacco because of various factors like high profitability, easy market access, fair price etc. The problem is to find out the factors contributing tobacco cultivation and to investigate the ethical issues of the tobacco growers in the area.

\section{OBJECTIVES OF THE STUDY}

The overall objective of the study is to estimate the factors influencing tobacco yield, and also investigate whether any ethical issues affect the production behavior of tobacco farmer in the study area. The specific objectives of the study are:

i. To assess the socioeconomic characteristics of the tobacco farmers in the study area;

ii. To investigate whether tobacco producers are concern about ethical issues of tobacco farming and its yield. ;

iii. To estimate the impact of contributing important variables on tobacco farming and yield; and

iv. To make some guidelines for the improvement of tobacco control policy in Bangladesh.

\section{LITERATURE REVIEW}

A considerable number of studies have been conducted in home and abroad regarding various issues of tobacco. "Tobacco" means any Nicotiana tabacum or Nicotiana rustica plant or any other related plants or its leaf or crop, root, branch or any part of it.(Tobacco Products Usage Control Act,2005)Berry and Porter (1986) in their study argued that there is no essential difference between the use of alcohol and tobacco and the use of opium and cannabis. The use of tobacco is both dangerous and addictive. For these reasons its production, distribution and consumption raise ethical issues which merit examination. He concluded that it is morally unacceptable as tobacco farming jeopardizes not only one's own well-being but also that of others. Scollo et al., (2016) stated that the child labor in tobacco farming is an ethical issues. It is common in many underdeveloped regions in which tobacco is grown. Globally, $60 \%$ of all child laborers between the ages of five and 17 years work in agriculture, which includes tobacco farming. Fox, B. J (2005) attempted to explore the importance of message framing and ethics in tobacco control. He concluded that some ethical principles are important for controlling tobacco farming. Ali et al. (2015) showed the socio-economic scenario of tobacco farming and its impact on environment. They argued that tobacco causes some serious disruption on environment. Tobacco farming has too much negative impact on biodiversity, livestock and poultry, soil and air. To control they suggested some necessary steps including strict rules and regulations, awareness building etc.Mahmud (1999) conducted a socioeconomic study on tobacco production in some selected areas of Rangpur district where he found that tobacco growing was a profitable business, but the Virginia variety was more profitable than the Matihari. Likewise many researchers, Hossain et al.(2013), Sarkar and Farida (2013), found the tobacco farming as a profitable than other crops. On the other hand, Nahar, F. and Efroymson, D.,(2007) showed in their case study that the high profitability of tobacco is nothing but a myth. Profitaility of tobacco is overestimated, and that there are various profitable and realistic alternatives to tobacco production. If the imputed value of own labor and that of their families' labor is taken into account, tobacco loses much of its profit margin, as the high labor cost reduces the net return to labor. According to UBINIG research work, there are several reasons including cash earning, perceived high profit, guarantee of inputs and market and also the involvement of farmers through company card plays a coercive role for continuing tobacco farming. She also showed that farming of non-food crops like tobacco by replacing food-crop land is a threat on our food security, soil fertility. For decades tobacco production has moved from one location to another, not due to the increased interest of farmers but rather due to the loss of soil fertility and destruction of sources of fuel wood in areas under 
production (Farida Akhter) .Khandaker (2012) designed her study with a view to assess the costs and returns as well as the profitability of growing tobacco. Tobacco production was highly profitable in the study areas. Production function model is estimated considering seven explanatory variables human labor, power tiller, seed, manure, fertilizer, insecticide and irrigation. It is found that most of the included variables of have significant impact on tobacco production. Very few studies are found on the issues of tobacco farming behavior of farmers with reference to their ethical concern. Almost none of the Bangladeshi researchers tried to estimate effect of the various contributing factors including ethics on tobacco yield. Especially no empirical study is conducted in Lalmonirhat region about ethical concerns of tobacco farmers. On this backdrop, the present study has attempted to meet up this research gap.

\section{METHODOLOGY OF THE STUDY}

Research methodology is the process of systematically solving the research problems. Methodology of this study includes selection of study area and sampling procedure, prepare of questionnaire, collection of data and analytical techniques.

\subsection{Selecting Study Area and Sampling Procedure}

Lalmonirhat, located in the north-west part, is one of the hotspots of Bangladesh where tobacco is grown commercially, tobacco farming is popular and on increase. Among the sub-district of Lalmonirhat, in Aditmari upazila this practice is comparatively higher. Considering these reasonable factors Aditmari upazila of Lalmonirhat district has been selected purposively for our study. After preliminary visit, 5 villages named Velabari, Sarpukur, Pathantuli, Tiperbazar and Kisamat Chandapur from Aditmari sub-district are selected randomly. Both qualitative as well as quantitative methods have been used to carry out this study. This study is based on both primary and secondary data. To collect primary data, from the tobacco farmers of the above five villages, 100 tobacco farmers, are interviewed randomly during October-November, 2016. Among the various types of tobacco such as Virginia, Motihari, Jati etc, Virginia is the most popular among the farmers in the study area. Thus only Virginia tobacco farmers are considered for our survey. The sample size of 100 is selected purposively, A well designed and pre-tested questionnaire is used which includes both open and close ended questions. The samples are selected in such a way that it covers all necessary information to examine our study objectives. Secondary data is collected from Bangladesh Bureau of Statistics (BBS).

\subsection{Analytical Framework}

In this study, tabular technique is followed to illustrate the overall socio-economic characteristics of tobacco farmers and to explore whether tobacco producers are concern about ethical and unethical issues of tobacco farming. Collected data are scrutinized, and summarized for the purpose of tabulation using the Statistical Package foe Social Science (SPSS) and Microsoft Excell-2010. Here, ethics is assumed to being aware about various harmful short- run and long-run effects of tobacco cultivation on public health, environment and society and thus having tendency of tobacco farmers to leave or decrease tobacco cultivation to some extent at least and replacing tobacco cultivated land by food or others cash crops production. Statistical analysis, an econometric regression model is used to estimate the factors (fertilizers, pesticides, seeds, labors, irrigation, and tobacco company support and land quality) particularly including ethics affecting tobacco yield. From the normative point of view, ethics of tobacco farmers is assumed as a factor of influencing tobacco production behavior.Positive economics describes the world the way it is. It uses scientific principles to arrive at objective, testable conclusions based on facts. Positive economics of tobacco production includes its causes, determining factors' of production, cost-benefit, profitability etc. Traditionally using positive economics approach, it is analyzed tobacco production behavior of the farmers.Normative economics, on the other hand, is not factual rather as a subjective issue it incorporates the opinions and underlying morals, ethics and standards. Normative economics of tobacco production raises question about consumption, production and distribution of tobacco considering its wider negative effects. It is assumed from the normative point of view, tobacco farmers' production behavior would be negatively related with their ethical concern towards their tobacco farming.

In our research, positive economic approach is used to determine the factors including ethics those are contributing in tobacco yield, and normative approach is used to investigate about ethical concerns of tobacco farmers in the study area. The following figure summarizes our analytical procedure: 


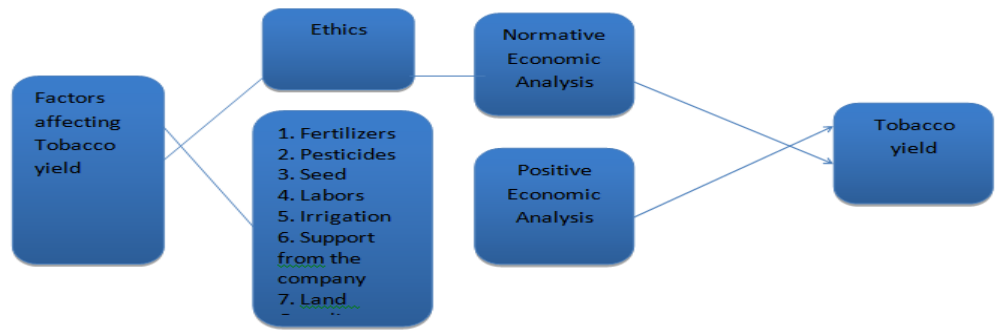

Source: Authors' own formulation

\section{.3 Empirical Modeling of Tobacco Yield Function}

To predict the quantitative impact of various variables including ethics on the tobacco yield, the following empirical generalized multiple regression model is estimated using the Ordinary Least Square (OLS) method. YIELD $=\beta 0+\beta_{1} F R T+\beta_{2} P S T+\beta_{3} L B R+\beta_{4} I R R+\beta_{5} L N D \_Q+\beta_{6} S E E D+\beta_{7}$ S_COM $+\beta_{8}$ ETHICS

$+\varepsilon_{i} \ldots \ldots . .(1)$

The model specified above also to be tested using double-log forms with a view to check functional form best fits the model. The double-log form of the model is specified by taking the natural log of dependent variable and continuous explanatory variables, leaving the dummy variables untransformed. The explicit form of double $\log$ form of the model is given as:

$\operatorname{lnYIELD}=\beta 0+\beta_{1} \operatorname{lnFRT}+\beta_{2} \ln P S T+\beta_{3} \ln \mathrm{lnR}+\beta_{4} \operatorname{lnIRR}+\beta_{5} \ln L N D_{-} \mathrm{Q}+\beta_{6} \operatorname{lnSEED}$

$+\beta_{7}$ S_COM $+\beta_{8}$ ETHICS $+\varepsilon_{i}$.

Where: YIELD $=$ Per bigha tobacco yield in $\mathrm{kgs}$ (Dependent variable)

Independent variables:

FRT $=$ Per bigha fertilizer nutrients in $\mathrm{kgs}$ (Urea/TSP/DAP/MAP/Others) applied.

$\mathrm{PST}=$ Pesticides/insecticides in kgs (Theovita,/Basudin/Ridomil/Singenta) applied per bigha).

$\mathrm{LBR}=$ No. of day labors worked per bigha ( Labor hours of all engaged in tobacco farming).

$\mathrm{IRR}=$ No. of irrigations.

LND_Q= Level of land quality.

( 1= Less fertile land, 2= Medium fertile land, 3= High fertile land).

SEED $=$ Per bigha seed used.

S_COM= Dummy variable for the support received ( easy loan, free seed, fertilizers) from tobacco company,

(Support received=1, Else=0 ).

ETHICS $=$ Dummy variable for ethics $(1=$ tobacco farming is unethical, $0=$ Otherwise $)$.

$\varepsilon_{\mathrm{i}}=$ Disturbance term

$\beta_{0}, \beta_{1}, \ldots \ldots, \beta_{8}$ are known as the parameters of the model or intercept and slope coefficients respectively.

\section{RESULTS AND DISCUSSION}

\subsection{Socio-economic background of Tobacco farmers}

The socio-economic characteristics and background of tobacco farmers influence their production to a great extent(Hassan et al.2015). In order to get vivid picture of socio-economic status of tobacco farmers ,this paper includes age, education level, family size, main occupation status, types of farmers based on farm size, farming experience, tenurial status, and status of receiving any support from tobacco company .Age: The socioeconomic characteristics of the respondents surveyed on the selected tobacco farmer in the study area are in Table 1. The results revealed that among 100 respondents, age of the major (32\% and 28\%) tobacco farmers ranged from 31 to 50 years. In general most of the respondents fell within the most economically active age of 31 to 50 years. Only $2 \%$ of the farmers fell within the age range of below 20 years, and $16 \%$ of farmers are within 21 to 30 years age range. It therefore indicated that few youths of this area engaged in tobacco farming profession. Being tobacco farming is a laborious job; few old farmers (55\%) are tobacco cultivator.

\begin{tabular}{|c|c|c|}
\hline \multicolumn{3}{|c|}{ Table: 1-Socio-economic characteristics of Tobacco farmers } \\
\hline Characteristics & $\begin{array}{l}\text { No. of } \\
\text { farmers } \\
(\mathrm{N}=100)\end{array}$ & Percentage \\
\hline Age level & 2 & 2 \\
\hline Below 20 years
\end{tabular}


Ethics and Economics of Tobacco Farming: A Case Study of

\begin{tabular}{|c|c|c|}
\hline 21 to 30 years & 16 & 16 \\
\hline $31-40$ years & 32 & 32 \\
\hline $41-50$ years & 28 & 28 \\
\hline Above 50 years & 22 & 22 \\
\hline \multicolumn{3}{|l|}{ Family size distribution } \\
\hline Small(1-3 members) & 33 & 33 \\
\hline Medium(4-6 members) & 49 & 49 \\
\hline Large(above 6members) & 18 & 18 \\
\hline \multicolumn{3}{|l|}{ Educational status } \\
\hline Illiterate & 37 & 37 \\
\hline Primary & 35 & 35 \\
\hline Secondary & 18 & 18 \\
\hline SSC or above & 10 & 10 \\
\hline \multicolumn{3}{|l|}{ Main occupation } \\
\hline Only farming & 58 & 58 \\
\hline Business & 31 & 31 \\
\hline Service & 8 & 8 \\
\hline Others & 3 & 3 \\
\hline \multicolumn{3}{|l|}{ Types of farmer (based on farm size) } \\
\hline Small(1-33 decimals) & 26 & 26 \\
\hline Medium(34-99 decimals) & 40 & 40 \\
\hline $\begin{array}{l}\text { Large( Above } 1.0 \text { acre or } 100 \\
\text { decimal }\end{array}$ & 34 & 34 \\
\hline \multicolumn{3}{|l|}{ Tobacco farming experience } \\
\hline Upto 5 years & 12 & 12 \\
\hline $6-10$ years & 23 & 23 \\
\hline $11-15$ years & 32 & 32 \\
\hline $16-20$ years & 18 & 18 \\
\hline Above 20 years & 14 & 14 \\
\hline \multicolumn{3}{|l|}{ Tenurial status } \\
\hline Tenant & 12 & 12 \\
\hline Owner & 49 & 49 \\
\hline Owner-cum-tenant & 39 & 39 \\
\hline \multicolumn{3}{|c|}{ Received any support from the tobacco company, } \\
\hline Yes & 54 & 54 \\
\hline No & 46 & 46 \\
\hline
\end{tabular}

Source: Field Survey, 2016

Family size: It is observed from Table-1 that, majority (49\%) of respondents have medium family(4-6 members) followed by 33\% of tobacco farmers having small family(1-3 members) and only $18 \%$ family belongs to large family(more than 6 members). Since tobacco is a labor intensive non-crop, it is very helpful for tobacco farmers if family size is larger.Educational status: Illiterate farmers or less educated farmers are generally more pursued in tobacco cultivation. Among the respondents, the maximum farmers (37\%) are illiterate while primary of 35\% and secondary of 8\%respondents. Farmers having SSC or above level education are $10.8 \%$ only (Table-1). It implies that more educated farmers have less tendency of tobacco production in general. Main occupation status: On the issue of main occupation status, only farming is the main source of earning for the majority (58\%) of respondents in the study area. It is also observed that $31 \%$ and $8 \%$ of the tobacco farmers earn mainly from business and service respectively (Table-1).Types of farmers: In the study area as shown in Table-1, 40\% respondents are medium farmers (farm size 34-99 decimals) followed by 34\% of respondents are large farmers ( 1 or more than 1 acre farm size). Only $26 \%$ of them are small farmers (farm size 1-33 decimals).Farming experience: It is shown in Table 1 the farming experience of respondents. $32 \%$ of the farmers have been farming tobacco for between $11-15$ years, while nearly 23 percent farmed for between 6 
to 10 years. For between $16-20$ years, $18 \%$ farmers and for more than 20 years, $14 \%$ farmers have been farming. Only $12 \%$ farmers have experience of only below 5 years. This could be inferred that, most of the farmers are well experienced and known about various impact of tobacco cultivation.Tenurial status: Table-1 shows that the highest numbers (49\%) of the respondents are owners followed by owner-cum-tenants (39\%) and tenant cultivators (12\%).Support from the tobacco company: In our study area, the most of tobacco farmers (54\%) get various types of support from the company. Generally the tobacco Company supports the contracted farmers through advice, easy loan, free seeds, fertilizers, pesticides, and guarantee of buying tobacco leaves at about higher price level. Besides, the company also supports the contracted tobacco farmers technically. Rest of the respondents does not get any support from the company, they are non- contract tobacco farmers(Table-1).

\subsection{Reasons for cultivating tobacco}

The preference for farming tobacco is not merely an independent factor rather it is interlinked with many social, economic and individual factors. The study uncovers some of the causes (not mutually exclusive) that lead to preference of tobacco farming. Major causes of tobacco farming are more profitability than other crops, having much money at a time, having easier market access, uncertain market price of other crops, ancestral occupation, having incentives (in loan, seeds, fertilizers, pesticides etc.) and technical supports from the company, Land is less suitable for other crops, having guarantee of selling tobacco leaves at fair price, encouraging from the tobacco company, and neighboring land factors as described in fig.-1.

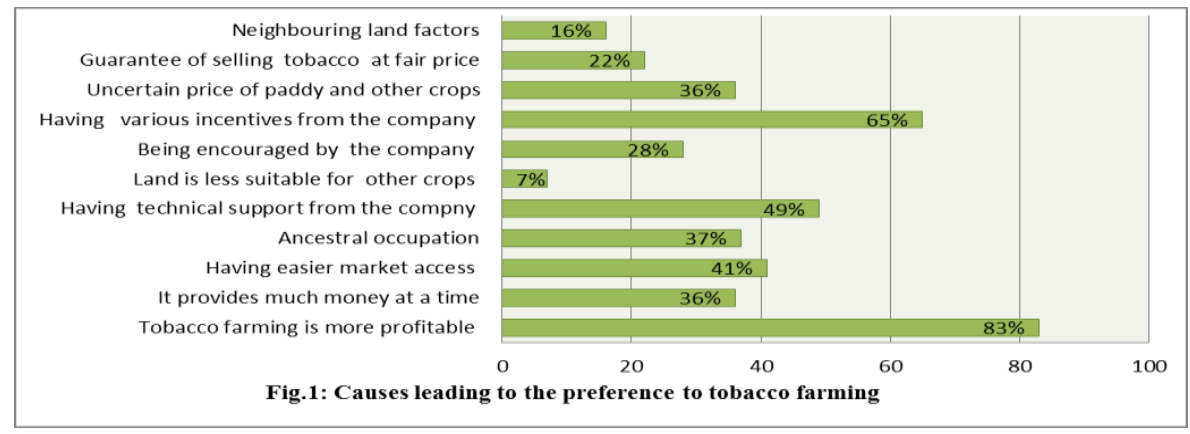

Source: Field Survey, 2016

\subsection{Ethical and related concerns of Tobacco farmers}

Ethics is a normative, and value judgment issue. The idea of ethics in tobacco farming differs from person to person. A tobacco farmer would consider not only personal cost-benefit but also social cost-benefit of it. He or she should consider the resulting short-run and long run negative impact on public health, society and environment. The tendency of farmers to cut or stop their tobacco farming considering its various negative issues on public health, society and environment is assumed as his/her ethics. The nature of ethics would include awareness about tobacco causing individual health and public health hazards, decline of soil fertility, environmental pollution etc. and making decision about tobacco farming. To investigate whether farmers are known about harmfulness of tobacco farming and what is their comments about validity of tobacco farming from ethical ground, summary of the opinion of the respondents about tobacco farming and its ethical related issues are described in table- 2 .

Table- 2: Opinion of the respondents about tobacco farming and its ethical related issues

\begin{tabular}{|l|c|c|c|c|}
\hline Opinions of the respondents & $\begin{array}{l}\text { Yes } \\
(\%)\end{array}$ & $\begin{array}{l}\text { No } \\
(\%)\end{array}$ & $\begin{array}{l}\text { Don't } \\
\text { know } \\
(\%)\end{array}$ & $\begin{array}{l}\text { Total } \\
(\%)\end{array}$ \\
\hline Tobacco production is harmful for health & 67 & 28 & 5 & 100 \\
\hline $\begin{array}{l}\text { Farmers should leave farming a crop although it } \\
\text { is beneficial for them but harmful for others }\end{array}$ & 73 & 18 & 9 & 100 \\
\hline Tobacco cultivation pollutes environment & 58 & 31 & 16 & 100 \\
\hline $\begin{array}{l}\text { Tobacco cultivation decreases soil fertility } \\
\text { gradually }\end{array}$ & 65 & 24 & 11 & 100 \\
\hline So Tobacco cultivation is unethical & 61 & 19 & 20 & 100 \\
\hline $\begin{array}{l}\text { And Farmers should stop or cut their tobacco } \\
\text { production }\end{array}$ & 21 & 73 & 6 & 100 \\
\hline
\end{tabular}

Source: Field Survey, 2016 
It is shown in the findings that $67 \%$ tobacco farmers of the study area say that it is harmful for health. Majority (73\%) of the farmers think that they should not produce a crop that is harmful for others but beneficial for them(Table-2). It reflects their common morality. Around 58\% reveals that tobacco cultivation pollutes environment and $65 \%$ respondents say that it leads to decline soil fertility gradually. Here it is implied that a significant number of farmers are not aware about tobacco related environmental hazards and fertility declining. Table 2 also shows that after successive queries about negative impact ,tobacco farmers are asked whether tobacco farming is unethical or not. In response of this question majority $(61 \%)$ of them claim that tobacco farming is unethical. But only $73 \%$ of them deny stopping or cutting their tobacco production (Table-2). This reflects their contradictory behavior with their claim. Therefore it is implied that majority farmers have no ethical concerns about tobacco farming.

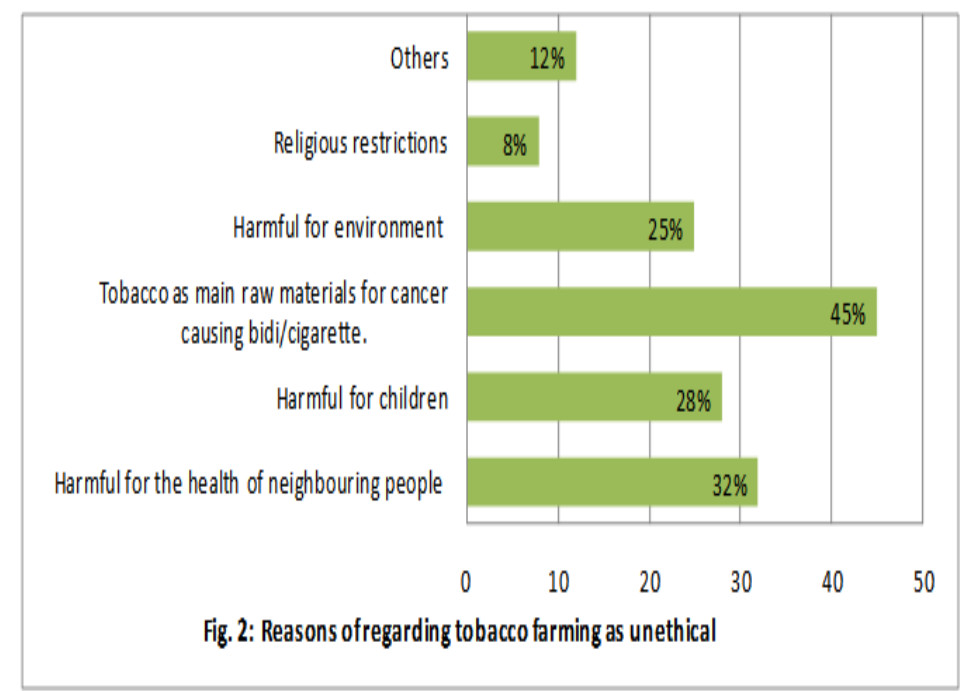

Source: Field Survey, 2016

Reasons for regarding tobacco farming as unethical are alluded in fig.-2. The respondents who reported that tobacco farming is unethical (Table-2) those viewed about the causes of being it as unethical. Generally most of the tobacco farmers have no proper knowledge about ethical issues of tobacco farming and its motives. The study reveals some of the causes (not mutually exclusive) that lead them to term tobacco production as unethical. Fig.-2 demonstrates that the dominant reported causes are being harmful for environment, for health of neighboring people and for children; religious restrictions; being tobacco as the main raw materials for cancer causing bidi or cigarette.Fig.-3 shows the moral or ethical satisfaction level of tobacco farming. It is clear from the figure that majority of tobacco farmers are not happy ethically for their tobacco farming. As they have some concerns about negative probable effects of tobacco farming. The result is conformity with the statement published in the Daily Star "Some farmers, who are aware about the harmful impact on soil fertility, want to stop tobacco cultivation (they don't get expected output for other crops in the land where tobacco is cultivated later on), but they have no option but to continue to produce tobacco" Thus it can be said that although many of the tobacco farmers are not satisfied with it but they have to cultivate it for various reasons.

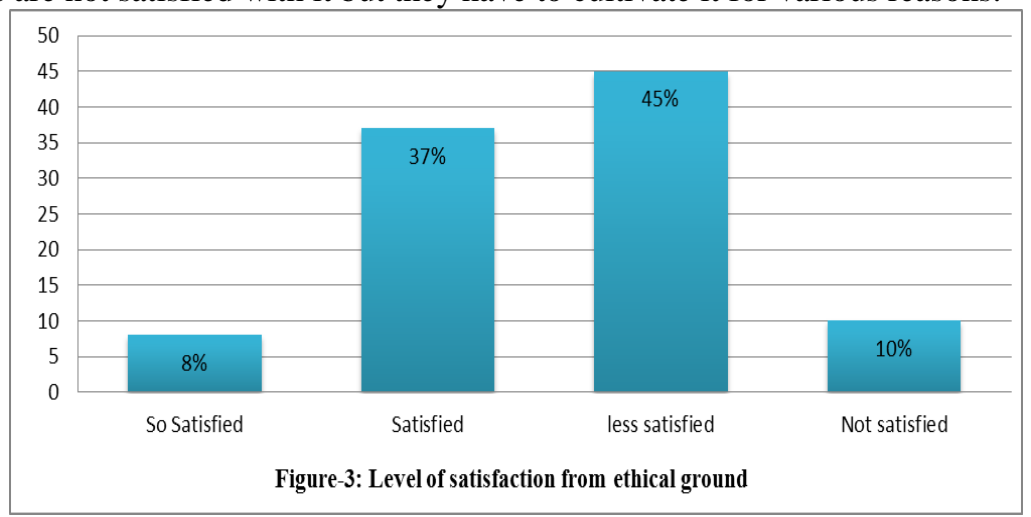

Source: Field Survey, 2016 


\subsection{Determining the factors affecting tobacco yield}

Regression model result shown in Table-3 is to measure the impact of the important factors on tobacco yield in the study area. Findings in the table indicates that output of the double-log regression gave the better result than that of linear regression model in terms coefficient of determination and number of significant parameters. Here, the coefficient of determination $\mathrm{R}^{2}=0.76$ suggests that 76 percent variation in dependent variable tobacco yield has been explained by the independent variables. Out of the eight regressors, six namely fertilizer, labor, support from the company, land quality, seed, and pesticides are statically significant, while the rest two (irrigation, ethics) are not statistically significant at various level of significance $(\alpha=1 \%, 5 \% \& 10 \%)$. With regards to the effect of individual variables, it is found out that fertilizer is significant at $1 \%$ level with positive impact; labor and support from company are significant at 5\% level with positive impact on tobacco yield. In the same way, pesticides, land quality, and seeds have positive effect on tobacco yield at $10 \%$ level of significance. The coefficient of this model represents the elasticity of tobacco yield with respect to independent variables. The coefficient of variable ethics is very small (0.000) and positive. It is clear from this result of double $\log$ model that there is no significant effect of ethics on tobacco yield in the study area(Table-3).

The result of linear regression model, shown in Table-3, reveals that $64 \%$ variation of dependent variable is explained by the eight independent variables. Here four variables namely fertilizer, labor, support from the company, and land quality, are statistically significant at $1 \%$ or $5 \%$ or $10 \%$ level of probability with positive impact on tobacco yield. But the rest four (irrigation, seed, pesticides, and ethics) are not statistically significant. Irrigation, seed and pesticides these three variables have insignificant positive effect on tobacco yield. In the same way ethics has some negative but no significant impact on tobacco yield.

Table-3: Result of the estimated factors influencing tobacco yield

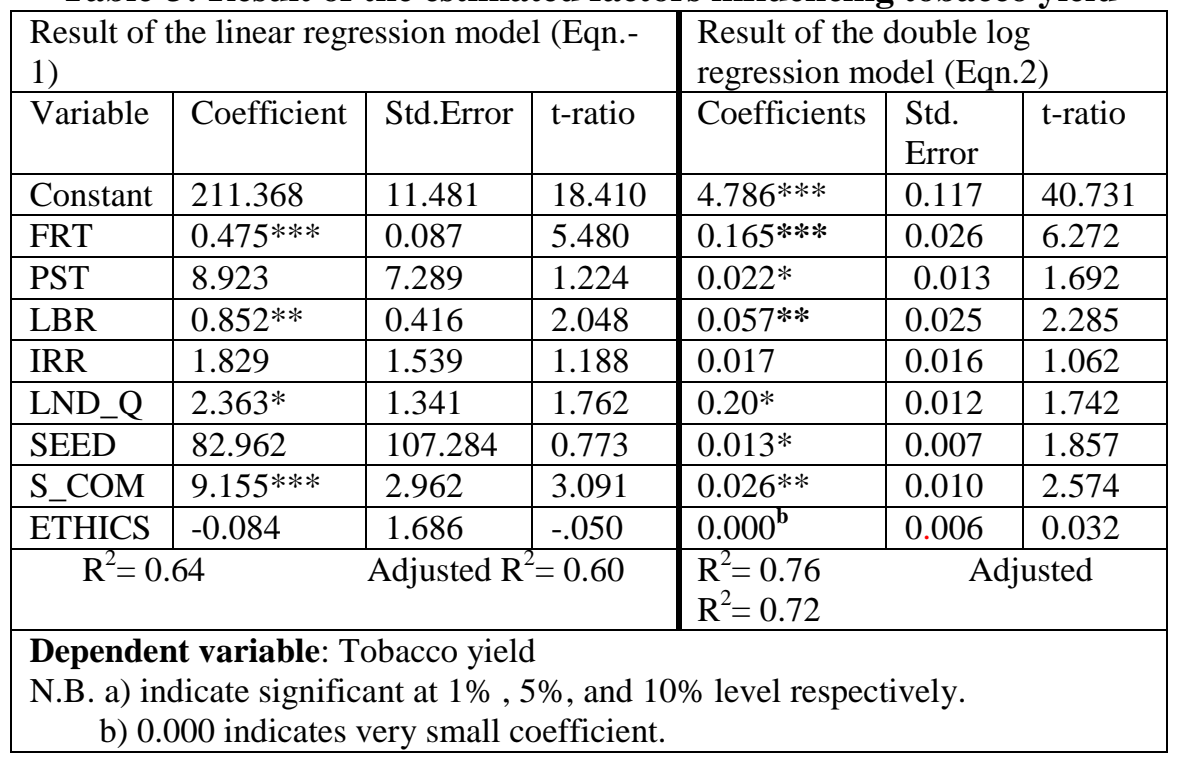

Source: Authors' own calculation

This is seen from the Table-3, although the linear regression model shows the negative relationship with tobacco yield as per priori expectation but both regression model results suggest that ethics has very insignificant relationship with tobacco yield.

\section{FINDINGS AND RECOMMENDATION}

The paper has made an attempt to assess the socio-economic background of tobacco farmers and estimate the factors including ethics influencing tobacco yield in the study area. The study shows that generally socio-economic situation of tobacco farmers is poor. Farming is the main means of livelihood for the majority $(58 \%)$ of tobacco farmers' family. A significant number of respondents $(37 \%)$ are found illiterate. Illiterate or less educated farmers are generally more pursued in tobacco cultivation. $67 \%$ of them have family members not less than 4 members. The paper finds that most of the members of the family including children, females work in the various stages of tobacco farming in the study area. A significant proportion of tobacco farmers (54\%) are producing tobacco by attracting various incentives or support from the tobacco company. Most of the tobacco farmers (83\%) termed tobacco farming is more profitable than other crops. The paper also finds other major causes of tobacco farming like having much money at a time, having easier market access, uncertain market 
price of other crops, ancestral occupation, having incentives (in loan, seeds, fertilizers, pesticides etc.). It is found from the study result that many of the respondents admits the negative impacts of tobacco farming and also $61 \%$ termed tobacco production is unethical. But their production behavior is not reflected by their claim of unethicality. They should cut or leave tobacco production from the ethical point view. It is shown in the study result, only $21 \%$ of them want to stop or cut tobacco cultivation from the next season. $73 \%$ of respondents are not interested to leave tobacco farming in the study area. The regression result shows the similar picture like many others researchers' findings. Among eight selected variables, six variables namely fertilizer, labor, support from the company, land quality, seed, and pesticides have significant positive impact on tobacco yield in the study area, while ethics, the most important variable in this paper, has very insignificant negative relationship with tobacco yield.

Tobacco controlling is one of the concern issues of policymakers in Bangladesh. From the supply side restricting tobacco farming is the important. For the improvement of tobacco control policy in Bangladesh, some recommendations are below:

- Social awareness should be developed and some awareness program should be arranged to stop tobacco production.

- The consciousness of the farmers about the negative impact of tobacco and its validity from ethical ground needs to be increased.

- The govt. and also NGO should provide easy accessibility of seeds, fertilizer, and other inputs to the farmers so that they are stimulated to use their land for food crops rather than tobacco.

- Necessary steps to be taken to ensure fair and stable price of food crops and minimizes the risk of damaging crops.

- Initiatives to be taken to spread out the idea about ethical legitimacy of tobacco farming through educational institutions, religious institutions (i.e. Mosque, temple), local Union council.

\section{CONCLUSION}

Tobacco production is harmful for the individual farmers, their families, public health, environment, and society. Thus tobacco controlling is the inevitable for Bangladesh. The government has been discouraging tobacco cultivation through the DAE, other agriculture and environment related organizations to save soil fertility and public health as well as environment from pollution. To regulate tobacco cultivation, it is taken various initiatives such as decision to stop loan facilities in tobacco farming by Bangladesh Bank, ban on using subsidized fertilizer in tobacco farming by the Agricultural Ministry but they are almost of no use. Further supply side measures should be taken besides demand-side regulations by the government. Farmers are farming tobacco instead of paddy and other crops after getting seeds, fertilizers and interest loan facilities from the tobacco companies. They are convinced by tobacco companies that it is more profitable than other crops. Many farmers are not interested to cultivate paddy and winter crops on their land as they often do not get fair prices because of poor marketing and transport. Realizing the disastrous impacts of tobacco farming, many of them now want to leave tobacco farming but they need alternative better options. Besides the government, NGO should come forward to provide various facilities to farmers so that they feel encouraged to cultivate food crops instead of tobacco.

\section{REFERENCE}

[1] Yearbook of Agricultural Statistics-2015, Bangladesh Bureau of Statistics, Available from www.bbs.gov.bd

[2] Barkat A, Chowdhury A.U., Nargis N, Rahman M, Kumar Pk A, Bashir S, Chaloupka FJ.(2012), "The Economics of Tobacco and Tobacco Taxation in Bangladesh," Paris: International Union Against Tuberculosis and Lung Disease, 2012

[3] Akhter, F. (2011), 'Tobacco Cultivation and its impact of food Production in Bangladesh', UBINIG. Retrieved from http://www.fairtradetobacco.org/wp-content/uploads/2011/07/Farida-Akhter_Tobacco-to-Food-Production.pdf (Accessed on 16 January,2017)

[4] Nahar,F. \& Efroymson, Debra.,(2007) Tobacco cultivation and poverty in Bangladesh: issues and potential future directions, Study conducted as a technical document for The first meeting of the Ad Hoc Study Group on Alternative Crops established by the Conference of the Parties to the WHO Framework Convention on Tobacco Control. Retrieved from www.who.int/tobacco/framework/cop/events/2007/bangladesh_study.pdf?ua=l(Accessed on 15 January,2017)

[5] World Health Organization, WHO Report on the Global Tobacco Epidemic, The MPOWER Package, Geneva: World Health Organization, 2008.

[6] Alam,D.S.,Ramasundarahettige,C.,Streatfied.P.K.,Nissen,L.W.,Chowdhury,M.A.,Siddique,A.T.,Ahmed,S.,and Evans, T.G.,(2013) 'Smoking-attributable mortality in Bangladesh: proportional mortality study' Buletin of the WHO, 'Smoking-attributable mortality in Bangladesh: proportional mortality study' Retrieved from:

[7] https://www.ncbi.nlm.nih.gov/pmc/articles/PMC3791659/ (Accessed on 14 January,2017)

[8] Geist, H.J.,(1999) 'Global assessment of deforestation related to tobacco farming' Tobacco Control,Vol-. 8, Pp 18-28 Retrieved from http://tobaccocontrol.bmj.com/content/8/1/18.full 
[9] (Accessed on 13 January,2017) Eliminating Child Labour in Tobacco Foundation annual report (2010). Eliminating child labour in tobacco growing. Geneva:ECLT2011,Availablefrom: http://www.eclt.org/site/wpcontent/uploads/2011/05/ECLTAnnualReport20101-11-final2_lores.pdf (Accessed on 15 January,2017)

[10] Yearbook of Agricultural Statistics-2012, Bangladesh Bureau of Statistics, Available from www.bbs.gov.bd

[11] The Daily Star,13 Janury,2016, http://www.thedailystar.net/rapid-increase-in-land-used-for-tobacco-cultivation12995,

[12] (Accessed on 08 March,2017)

[13] Amendment of Smoking and Tobacco Products Usage (Control) Act, (2005). Bangladesh Gazette, Published by authority of Bangladesh National parliament.

[14] Berry,G., and Porter,A., (1986)'Tobacco and ethics', Joural of the Royal College of General Practitioners, Retrived from

[15] https://www.ncbi.nlm.nih.gov/pmc/articles/PMC1960591/pdf/jroyalcgprac00152-0041.pdf on January 10, 2017

[16] Scollo, M.M, and Winstanley, M.H. (2016) 'Tobacco in Australia: Facts and issues' Melbourne: Cancer Council Victoria; 2016. Available from http://www.eclt.org/about-child-labour/about-child-labour-in-tobacco-growing/ (Accessed on 12 January,2017)

[17] Fox, B. J, (2005) 'Framing tobacco control efforts within an ethical context' (Available from http://tobaccocontrol.bmj.com/ on January 10, 2017 - Published by group.bmj.com)

[18] Ali, M.Y., Islam,M.F., Rahman.M.R., Sheema,M.K., and Akter,R., 'Tobacco Farming in Bangladesh and Its Impact on Environment'(2015) IOSR Journal of Environmental Science, Toxicology and Food Technology (IOSRJESTFT).Volume 9, Issue 12 Ver. III (Dec. 2015), PP 27-33 Retrieved from www.iosrjournals.org (Accessed on 12 January,2017)

[19] Mahmud, S. (1999): A social Economic Study on Tobacco Production in Some Selected Ares of Rangpur District. An Unpublished M.S Thesis Faculty of Agricultural Economics and Rural Sociology, Bangladesh Agricultural University, Mymensingh, Available from article.sciencepublishinggroup.com/pdf/10.11648.j.ijefm.20150302.13.pdf, (Accessed on 16 January,2016)

[20] Hossain, M.M and Rahman, M.M. ,(2013)A Socioeconomic Analysis on Tobacco Cultivation in Kushtia District of Bangladesh, Social Sciences. Vol. 2(3), 2013, 128-134.

[21] Khandaker,A.(2012) An Economic Analysis of Virginia Tobacco Production in Some Selected Areas of Kalihati Upazila in Tangail District, An unpublished thesis, Department of Agricultural Economics, Bangladesh Agricultural University, Mymensingh, Available from http://dspace.bau.edu.bd/handle/123456789/592 (Accessed on http://dspace.bau.edu.bd/handle/123456789/592

he Dhaka Tribune, 21 Januaary,2014,http://www.dhakatribune.com/agriculture/2014/jan/21/

[23] more-poor-farmers-turning-tobacco-cultivation\#sthash.nGCy30lw.dpuf (Accessed on 08 January,2017 